generation to generation. It waxes and wanes in complexity but never begins de novo"'. But he has an ungainly style of writing: talking of human attributes, he says "As a group they span the biological, behavioral, and social realms, constituting a kind of slope between animal and human states along which our species has moved evolutionarily and continues to cycle generationally"'.

Although there is much discussion about "circumventing the oviduct", a valuable opportunity is missed by failing to compare this with "circumventing the penis"; the ethics of artificial insemination, whether by donor or husband's semen, have been widely discussed in recent decades. On the technical side, it is disappointing to find no mention of ultrasound, which is now widely used as a non-invasive way of monitoring follicular development. There is no discussion of interspecific fertilization, and yet use of denuded hamster oocytes to bioassay the fertilizing capacity and examine the karyotype of human spermatozoa has been an exciting recent technical advance, one which still seems to send an ethical shudder through the World Health Organization.

As for the mistakes, how unfortunate to depict luteinizing hormone as a secretory product of the posterior pituitary gland; how naive to believe that infertility in men is often the result of a low sperm count, so that merely increasing sperm density by centrifuging a semen sample will increase fertility. Recent evidence from hamster oocyte preparations shows quite clearly that oligospermic men are infertile because of some basic defect that results in the ejaculation of small numbers of spermatozoa each of which has a significantly reduced fertilizing potential; concentrating the ejaculate is therefore a waste of time. And Edwards and Steptoe, who after all pioneered this whole field, will be interested to hear that the work was done at Oldham Hospital in Cambridge, England! Not a book to recommend.

R.V. Short is Director of the MRC Unit of Reproductive Biology, Edinburgh.

\title{
Lessons for twentieth-century nutritionists
}

\section{John Rivers}

\author{
Nutrition and Nutritional Diseases: The \\ Evolution of Concepts. By Karl Y. \\ Guggenheim. Pp.378. ISBN 0-669-03950-0. \\ (Collamore Press, Massachusetts: 1981.) \\ $\$ 21.95$.
}

AlThOUGH this is an important book, it must be admitted at the outset that it is not a historian's history. Professional historians of science will no doubt be irritated by the brevity with which many subjects are necessarily treated and by the occasional lapses that suggest historical naivety (for example, calling Boyle's school "Eaton", or seeming to equate Pereira's training as an apothecary with pharmacy not medicine).

But whatever its reception by historians, nutritionists will I hope buy and read this book, for it is an important history of their discipline and their profession, and one that they should study. It is all the more valuable because Professor Guggenheim is not a trained historian, but a nutritionist who, after a lifetime of research into the practical problems of nutrition, has produced this scholarly work in his retirement.

The discipline of nutrition is an uneasy coalition. Its scientific roots are in aspects of physiology which had their heyday in the nineteenth and the first half of the twentieth centuries. Its justification is a wide spectrum of unresolved practical problems, from tooth decay to the world food problem. And nutritionists, it must be admitted, are people who, by and large, fail either to revive the science or solve the problems to which it is addressed. As long as it is possible to imagine that, even if the next experiment won't save the starving masses at a stroke, it is a step in that direction, then there is an excuse for surfing along on the wave-front of the present. But as it increasingly appears that poverty not protein is the key to malnutrition, and that tooth decay can only be cured by drawing the teeth of the confectionery industry, the nutritionist increasingly needs to take stock and decide whether he is really necessary.

Individual action is of course irrelevant. What is needed is a dialogue within and beyond the profession about the extent to which nutritional science should be coupled to practical policy. Such a discussion would need to be guided by a coherent view of the past, and without the historian's spotlight can probably never begin. It is self-evident that such historical studies on nutrition as exist at present have not had any such catalytic role - not surprisingly, for where they are not social histories of diet, they are catalogues of achievements of the great and famous.

The significance of Professor Guggenheim's new book is that it is free of that tradition and hopefully will have a powerful impact. He does not merely retell the story of the development of the science of nutrition, but, more than any other work on the subject, he studies its growth mechanisms. His avowed aim is contained in the subtitle - he tries to trace "the evolution of concepts". He does so with great fluency, and in a way that is realistic, in that it sees the concept as dominating the fact. Moreover, he makes his account relevant to today's problems by devoting a large part of the book to focusing "attention on the conceptual evolution of five principal issues that . . . dominate nutritional thinking until our own time". In doing so he has chosen well, and his discussions on the concept of an adequate diet, on protein and on the origins of the dietary thermogenesis controversy (recently revived in Nature) are all very valuable.

I am slightly disappointed by the fact that, inasmuch as he looks beyond internal imperatives for the growth of nutritional science, his horizon is the parallel growth of ideas in other areas of science. Highlighting this feedback is valuable, and he provides the best discussion of such interactions that is available in a popular work. But it is a pity that he did not extend his view and concentrate more on general social history and the extent to which nutritional science was also moulded by the general ethos of the society in which it was developed. In his failure to do so, his work raises questions it cannot answer. For example, his treatment of the evolution of concepts of protein and energy metabolism in the nineteenth century, while meticulous and well worth reading, is for me incomplete. I cannot believe that the subject can be fully explored without discussion of the social values that predicted it, stimulated both the research and its acceptance, and dictated its conceptual framework. Nutrition developed in the new Europe where both workhouse and standing army grew up, and the state required dietetic advice on subsistence requirements for the poor, and optimal provision for its fighting men.

It is surely no coincidence that in this environment nutritionists adopted models which involved the idea that both minimal

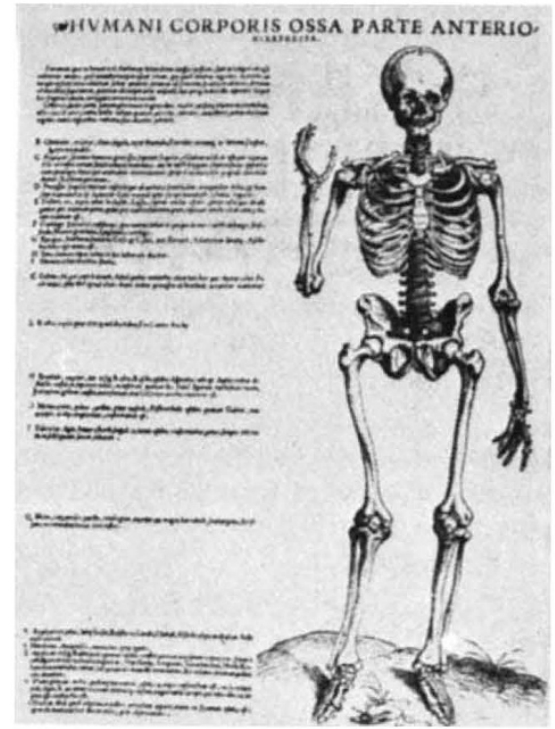

Skelcton of a rachitic male, depicted by $\mathrm{A}$ Vesalius in Tabulae Anatomicae Sex (1538). Rickets was apparently so prevalent that Vesalius regarded the skeleton, of an adult with late rickets, as normal. 
(subsistence) requirements and higher JOURNALS SCIENTIFIC
BOOKSHOP

H.K. LEWIS can supply works in all branches of Pure and Applied Science. Catalogues on request. Please state interests.

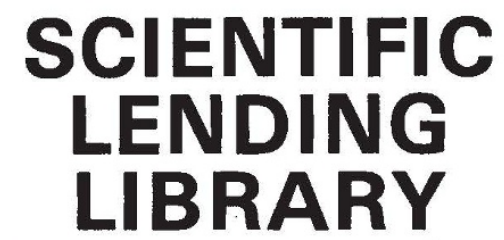

Annual Subscription from $\mathbf{f 8 . 5 0}$ (Available in U.K. only)

Reduced rates for multiple subscriptions.

\section{Prospectus post free on request.}

Quarterly List of New Books and new editions added to the Library sent post free to subscribers regularly.

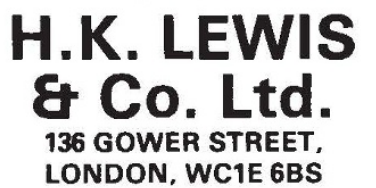

optimal intakes existed? And surely the tenacity with which they clung to the idea of a special role for protein related to the social value of protein food such as meat.

But for all that Professor Guggenheim's book does not provide any solutions to such problems, it makes it clear that they exist to be solved. I hope the fluency and clear erudition of this book will encourage others to read it, to consider the same questions and, perhaps, to provide some answers.

John Rivers is a Lecturer in the Department of Human Nutrition at the London School of Hygiene and Tropical Medicine, University of London.

\section{Hectares for whom?}

\section{John Andrews}

Farming and Wildlife. By Kenneth Mellanby. Pp.178. ISBN 0-00-219239-X. (Collins: 1981.) £9.50. Countryside Conservation: The Protection and Management of Amenity Ecosystems. By Bryn Green. Pp.249. ISBN hbk 0-04-719001-9; ISBN pbk 0-04-719002-7. (George Allen \& Unwin: 1981.) Hbk £13, \$35; pbk £6.95, $\$ 17.95$.

SINCE prehistoric times, agriculture has been the major modifier of the world's terrestrial habitats; even the marine environchemicals. In those countries where there is an active nature conservation lobby, relations with farming interests have become progressively more strained over the past 30 years as modern agricultural techniques have made rapid inroads into wildlife communities which had long coexisted with traditional farming methods. Inevitably, both sides have tended to misrepresent the situation to some degree and Professor Kenneth Mellanby's Farming and Wildlife provides a valuably calm and dispassionate appraisal of the effects of each on the other.

The opening chapters of the work deal in general terms with the impact of man on Britain's natural habitats and wildlife over the last 7,000 years, and more specifically with the effects of changing methods in arable farming, grassland management and livestock production since 1945 . Greatly increased productivity from existing farmland has been won at the expense of a vast reduction in the population of until recently common and widespread wildlife, of which our native flowers and butterflies are perhaps the most regretted loss. At the same time, the profitability of farming and the incentives of grant aid have brought much marginal land reducing many species which were already ment has been affected by the run-off of silt, organic nutrients and latterly of agrointo intensive production, severely rare. The middle section of the book looks in some detail at the features of typical lowland farms over which most public concern has been expressed - the soil itself; hedges and trees; and ponds, rivers and marshes.

Thus far the book contains much that will come as news to farmers who are often profoundly ignorant about the wildlife on the land and their own effects on it. By contrast, the final section contains much to inform the concerned but of ten equally illinformed public about pests and pesticides, diseases of livestock and about field sports, which indirectly contribute to the retention of habitats and hence of wildlife in the countryside.

Farming and Wildlife is well illustrated and readable. No doubt conservationists will read it. The question is, will farmers?

Professor Mellanby deliberately eschews the political aspects of farming and wildlife, in particular the questions of whether increased agricultural output is economically justified and whether society should be able to control rural land use change where public loss of amenity is significant. However, these questions are examined with skill and relish by Bryn Green in Countryside Conservation.

It is timely that conservation, which has become an increasingly complex and skilled profession, now has its first textbook, and entirely apposite, given that the conservation movement is fighting desperately for what it believes in, that the textbook should also be a confident and wellargued assertion of its case.

Part 1 is devoted to conservation concepts, the impact of man on his environment and the development of conservation in Britain. In Part 2 the author examines the characteristics of natural ecosystems and explains the impact of land use change on all our major habitat types: agriculture figures largely, but forestry, industrial and urban development, recreational impact and pollution are given comparably thorough coverage. Conservation considerations aside, one is reminded again that land use management in Britain, where every hectare counts, is in appalling disarray, with blinkered state agencies each pursuing its own special interest regardless of the general good.

The concluding section of the book examines the present methods for selection and protection of land of conservation importance, and argues that a new approach is required if we are to save the remaining areas of scientific importance and the natural beauty of the countryside.

A welcome departure from the somewhat petulant "smocks and windmills" approach of some recent writers, Bryn Green's book contains much to instruct and to inspire a hard-headed approach to the massive problems which the conservation movement now faces.

John Andrews is Head of Conservation Planning at the Royal Society for the Protection of Birds, Sandy, Bedfordshire. 